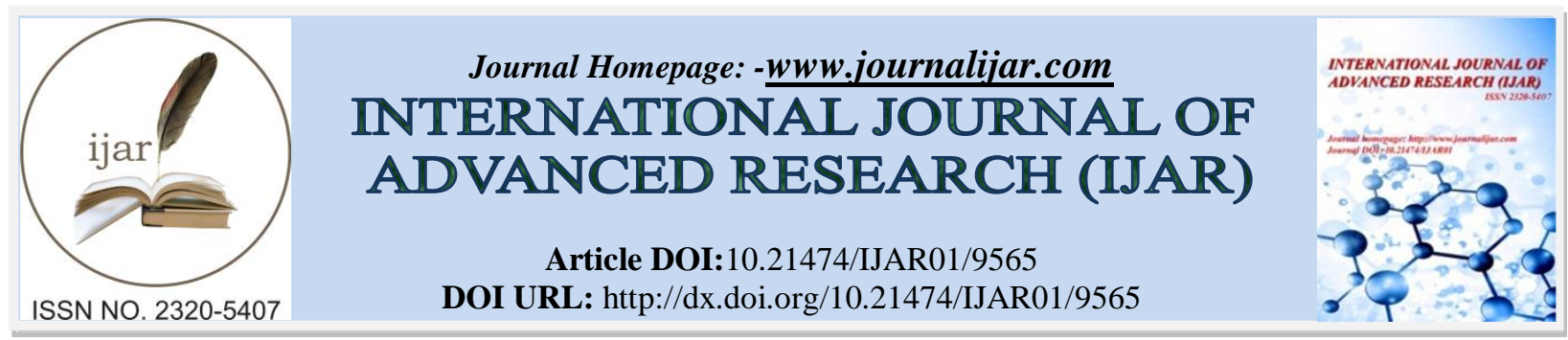

RESEARCH ARTICLE

\title{
INVESTIGATING ASSIMILATION AND METHATHESIS PROCESSES IN MAZANDARANI LANGUAGE, MARZOUN KOLA VARIETY.
}

Fatemeh Yazdani ${ }^{1}$ and Dr. Foroogh Kazemi ${ }^{2}$.

1. M. A of Linguistics, Central Tehran Branch, Islamic Azad University, Tehran, Iran.

2. Associate Professor of Linguistics, Central Tehran Branch, Islamic Azad University, Tehran, Iran.

\section{Manuscript Info}

Manuscript History

Received: 12 June 2019

Final Accepted: 14 July 2019

Published: August 2019

Key words:-

phonological processes, assimilation, methathesis, Mazani dialect, Amoli variety.

\begin{abstract}
The present study aims at analyzing assimilation and methathesis processes in Mazandarani dialect of Marzoun Kola, located 5 kilometers away from Amol city. This area has been under the rule of Iran since Sasanuan dynasty. Hence, the effect of Sasanian Pahlavi Language on Tabari language has been more than any other language. The question presented in this paper is how are different kinds of assimilation and methathesis in Mazani dialect? It is a field study which has been done through interviews with speakers in this area. The results indicate that all kinds of assimilation are seen in Mazani dialect: vowel to vowel assimilation, and vowel to consonant assimilation are seen more frequently than consonant to consonant assimilation. Progressive assimilation is more frequent than retrogressive assimilation. Complete and incomplete assimilation and assimilation regarding neighborhood and non-neighborhood are equal. Also methathesis phonological process is seen in this variety which is bolder in the discourse of uneducated people. Investigation of phonological processes of Mazani dialect is closely related to standard Persian.
\end{abstract}

Copy Right, IJAR, 2019,. All rights reserved.

\section{Introduction:-}

Phonetics and phonology are sub-fields of linguistics. Linguistics deals with speech language at first place; there for the first task of someone who describes phonemes is to represent the speech flow. Phonological processes imply a kind of structural change in phonemic characteristics or components (Bijan Khan, 2005, 185). Due to combined companionship, Phonological units are exposed to changes which are called phonological process. In spite the fact that the official language of a country influence many dialects and has caused a lot of phonological changes and differences, analyzing them can facilitate recognition of lingual evolutions and transformations; it can also be effective in enriching Persian language and creating new words and removing foreign words. The southern coast of Caspian Sea was known as Tabarestan before the invasion of Mongols. Since the $7^{\text {th }}$ century AH, coincident with Mongol invasion, Tabarestan hasn't been used and the word Mazandaran, sometimes meaning a part of Tabarestan and sometimes being synonymous to it, has been used instead. Mazandarani language (Mazani, Mazarouni, or Tabari) is one of the languages in northwest of Iran which is in the group of languages on the coast of Caspian Sea. It includes languages like Zazaki, Gourani, Harzandi, Taleshi, Gilaki, Mazandarani, and Semnani, which are historically related to Parthian Pahlavi language. The present study deals with two phonological processes which are assimilation and methathesis in MarzounMazani specie. The importance of this paper lies in presenting the culture, 
customs, and the forgotten history of an area. It's worth mentioning that by the time and for different reasons including the effect of different media, many of these dialects including Mazani will be forgotten. Collecting, analyzing, and investigating the dialects from the linguistics point of view can prevent them from being forgotten and extinct.

Mazandarani is spoken only in Iran. It is distributed in the northern half of the country, and except Mazandaran whose name is taken by the language, there are people in Golestan, Tehran, and Semnan who speak in this language. Two questions are stated in the present study: what are the different types of assimilation in Mazani specie? How is the nature of methathesis process in Mazani? The study has been done on the language specie in Marzoun kola located $5 \mathrm{~km}$ away from Amol. It has been done in field method through interviews with Mazandarani speakers. Of course, we have used books about the grammar of Farsi and a few existing written resources about this dialect in writing this paper.

\section{Review of Relevant Studies}

Cohn (1990; 1993) points out that English vowels become nasalized before nasal consonants, which she ascribes to a phonetic process of regressive nasal assimilation. "If ... nasalisation typically affects only a portion of the preceding vowel and is observed to occur in a gradient manner, it should be concluded that the nasalisation is the result of phonetic implementation rather than a phonological rule." Cohn shows that Sundanese vowels also participate in nasal assimilation — vowels assimilate the nasality of an immediately preceding sound — but she argues that the process in question is phonological.

Trask (2003:12-13) believes language changes don't take place every century; they don't take place even annually; he believes that languages are evolving daily, while most of the people aren't aware of this fact. A common language evolution is change at phoneme level which includes any kind of change in phonemes system and their distribution. Trask (2003) suggests that phonological changes have been investigated more than any other language changes and date back to 200 years ago.

Janssen (2007) has written an article titled "phonetic vowel, phonemic voicing, and assimilation in English" in which the author has investigated special aspects of retrogressive assimilation process in voicing in obstruent clusters in English physically and quantitatively. This author has suggested that voiceless obstruent /s, t/, voiced obstruent /z/ and to some extent /d/ cause assimilation in voicing of the previous obstruent. The results of investigation of the phonological effect on the above mentioned processes indicate that it's better to analyze them according to synchronous movements of speech organs which is based on the physical characteristics relevant to phonetic contrast in voicing characteristic.

Chrystal (2008, 40) divided assimilation into two groups with regard to the degree of similarity: complete assimilation and incomplete assimilation: "sometimes a phoneme may lose one or two of its phonetic characteristics, or take one or two phonetic characteristics of the neighboring sound, and hence face to a phonetic change. Metathesis frequently occurs in all languages as a type of speech error and is a common feature of child phonology (Spencer 1996: 68). Metatheses are well recognized in historical linguistics...but they can also be seen in performance errors, in such tongue-slips as aks for ask, or in the phenomenon of 'spoonerisms'(Crystal 1997:240).

Blevins and Garrett (1998: 527-529) categorize the Rotuman alternation as compensatory metathesis. Historically, this entails an anticipation or perseveration of vowel features across an intervening consonant toward the stressed vowel, leading to "extreme vowel-to-vowel coarticulation." In Rotuman there would have been anticipation of the final vowel in the direction of the preceding stressed syllable, followed by loss of the final vowel, essentially /hosa/ $>$ /hoasa/ > /hoas/.

Explaining methathesis process, Hium (2006) refers to the fact that explaining why methathesis takes place, has a cognitive nature. There is a consensus that an important factor causing methathesis is ambiguity in listening symbol. Estaji (1990) has studied phonemic methathesis, and has considered this process as a systematic and regular phenomenon. Investigating the historical data, she considers the audibility principle responsible for this process; while regarding other data, she acknowledges it's not possible to talk about regularity of methathesis process, because in some cases the output of methathesis process reverses audibility sequence. 


\section{Theoritical Framework}

Phonology is the subfield of linguistics that studies the structure and systematic patterning of sounds in human language. The term phonology is used in two ways. On the one hand, it refers to a description of the sounds of a particular language and the rules governing the distribution of those sounds. On the other hand, it refers to that part of the general theory of human language that is concerned with the universal properties of natural language sound system(Akmajian, 2010: 109-110).

Phonology studies how sounds are organized in particular languages. It tries to discover the psychological patterns and underlying organization of sounds shared by native speakers of a certain language.

\section{Phonological processes}

A phonological process is a mental operation that applies in speech to substitute, for a class of sounds or sound sequences presenting a specific common difficulty to the speech capacity of the individual" and that "A phonological process merges a potential phonological opposition into that member of the opposition which least tries the restrictions of the human speech capacity". What Stampe is suggesting is that when a child is unable to produce a sound, they will employ some form of substitution to the word to make it producible. However, Stampe is keen to stress "These substitutes are not merely random or occasional, but are regular and unexceptional in the child's speech". Stampe writes "non-occurrence of certain sounds in the underlying representation of a language is attributed to a process in the phonological system of the language". What Stampe is suggesting is that there are variations in phonological processes between languages and that these are due to variation in the phonological system of the language used (Stampe, 1979).

\section{Assimilation}

Assimilation is a process by which a sound becomes more like a nearby sound. A common phonological process involving the feature [strident] is called assimilation. This term refers to instances where one part of a word (say, the onset of a syllable) becomes more like another in terms of one or more distinctive features. Progressive assimilation is where one part of a word becomes more like a preceding part.

Regressive assimilation is where one part of a word becomes more like a following part. $\bullet$ For example, in Bukusu, a Bantu language of Kenya, (onset) [lateral] changes to (onset) [rhotic] in suffixes which attach to a stem with (onset) [rhotic] (Odden 1994; Hansson 2010).

\section{Metathesis}

Metathesis :Two sound (usually adjacent) switch their place. Rules may be obligatory (all speakers do it; e.g., final devoicing in Czech or nasalization of vowels in Czech/English) or optional (sometimes or some speaker do it). In more recent nonlinear phonology, metathesis has resisted a unified, explanatory treatment despite advancements in the formalism used to account for many other processes, such as assimilation (Clements 1985) and dissimilation (Odden 1987).

Thus, from a theoretical perspective, metathesis ceased to exist as a distinct phonological process (Wanner 1989). More recently, Hume (1998a) also argues that some cases of consonant/consonant metathesis defy analysis given the accepted constructs of nonlinear theory, such as the No Line Crossing convention. For most of the twentieth century, metathesis was described either in prose or, as formalisms became more sophisticated, as reorderings of indexed objects in a string. Chomsky and Halle (1968: 361) describe metathesis as "a perfectly common phonological process," and permit transformations that effect permutation. In their notation, /skt/! [kst] metathesis in the need for indexation distinguishes metathesis from most other processes, such as insertion, deletion, and featural assimilation.

Metathesis is another phonetic evolution from the middle age that makes the pronunciation of the words easier. It is relocation of phonemes in the words (Bagheri, 1998: 148, Kalbasi, 1991: 76). Metathesis process has been analyzed from different points of view including historical, social, phonological, psychological, and typological points of view. From the historical point of view, it's a process in which the linear arrangement of the elements changes at a special point in the history. Normally, metathesis is not considered a systematic process, but it is treated as a secondary and subordinate process among other kinds of phonetic processes. Stoneham (2006) states that metathesis process can be considered as a phonetic restoration strategy making the elements follow a pattern which the language prefers. 


\section{Data Analysis}

The data in this paper includes Mazandarani speech investigated from assimilation and metathesis points of view. The attendants' speech is produced unconsciously in Mazandarani dialect of Marzoun Kola village. The produced sentences were then analyzed as follows:

Sample 1) The man went to the storehouse. mærdiburdesæmteæmbar

Sample 2) It is snowing heavily: xæleværfene

Sample 3) They robbed the bank: azbank dezzihakerdene

As it is seen in the above samples there is vowel to vowel assimilation in the word "ænbar" (storehouse). In the first sample the consonant $/ \mathrm{n} / \mathrm{which}$ is a nasal consonant is affected by the following consonant $/ \mathrm{b} /$ and has been transformed to the bilabial consonant $/ \mathrm{m} /$. In the second sample in the word "Bærf" (snow) the consonant $/ \mathrm{b} /$ has been transformed to the consonant $/ \mathrm{v} /$ which is a labiodental consonant; there is evidence in linguistics indicating a similar behavior among the labiodental consonants and bilabial consonants in phonological processes. In the last sample the consonant /d/ in the word "dozdi" (Dezzi which means robbery) has been transformed to the consonant /z/ affected by the precedent consonant / $\mathrm{z} /$ which is a complete assimilation and indicates that the assimilation with the neighboring phonemes is only complete assimilation. Obstructive coronal assimilation of $t$ and $d$ is with the fricative consonants $\mathrm{s}$ and $\mathrm{z}$; in this kind of assimilation producing fricative to obstructive phonemes is extended. $\mathrm{n} \rightarrow \mathrm{m} /[\mathrm{b}, \mathrm{p}, \mathrm{m}, \mathrm{v}, \mathrm{f}]$

Table 1:-examples of consonant to consonant assimilation in Mazandarani. Amoli (Marzoun Kola village)

\begin{tabular}{|c|c|c|c|c|c|c|c|}
\hline row & Meaning & Before & \multirow{2}{*}{$\begin{array}{c}\text { After } \\
\text { assimilation }\end{array}$} & assimilation & \multicolumn{4}{|c|}{ Assimilation type } \\
\cline { 5 - 7 } & & $æ n$ degree & direction & structure & Adjacency \\
\hline 1 & storehouse & $æ m b a r$ & incomplete & retrogressive & c-c & Adjacent \\
\hline 2 & snow & bærf & værf & incomplete & progressive & c-c & Non-adjacent \\
\hline 3 & robbery & Dozdi & dezzi & Complete & progressive & c-c & Adjacent \\
\hline
\end{tabular}

Sample 4) Where is the pot?

digkube?

Sample 5) The dog takes care of the sheep.

sæggællegesfændepene

Sample 6) Father went hunting.

perburdešikar

Sample 7) Put sugar in your tea.

ŠeČaidærunŠikærdæken

Sample 8) Do you work at the weekend?

axærehæftehakarkenni

In samples 4 and 5 the consonant $/ \mathrm{J} /$ has been transformed to the vowel $/ \mathrm{g} /$ that is the assimilation between body explosive consonants and the following vowel. It can be said that the frequency of [c, $\mathrm{J}]$ is more than the frequency of $[\mathrm{g}, \mathrm{k}]$ in Amoli specie. Phonetic representation in infrastructure is assumed to be [c, f], which changes in some phonetic textures and becomes $[\mathrm{g}, \mathrm{k}]$.

In samples 6 and 7, as it is seen in table 2, the vowel/e/ has changed to the vowel/i/; the vowel/e/ gets assimilation in vicinity of the phonemes $\breve{Z}$ ، $\breve{S} ، \breve{C}$ ، $\breve{j}$ that means it loses its semi-closed characteristic /e/ and transforms to the closed /i/. The phonemic rule is as follows: 
$\mathrm{J} \rightarrow \mathrm{g} /-\{\mathrm{k}\}$

It is seen in sample 8 that the velar consonant /c/ before the following vowel /a/ becomes the soft velar consonant $/ \mathrm{k} /$ that is as follows:

$\mathrm{c} \rightarrow \mathrm{k} /-\mathrm{a}$

Table 2:-examples of consonant to vowel assimilation in Mazandarani. Amoli (Marzoun Kola village)

\begin{tabular}{|c|c|c|c|c|c|c|c|}
\hline \multirow[t]{2}{*}{ row } & \multirow[t]{2}{*}{ Meaning } & \multirow{2}{*}{$\begin{array}{c}\text { Before } \\
\text { assimilation }\end{array}$} & \multirow{2}{*}{$\begin{array}{c}\text { After } \\
\text { assimilation }\end{array}$} & \multicolumn{4}{|c|}{ Assimilation type } \\
\hline & & & & degree & direction & structure & adjacency \\
\hline 4 & Pot & dij & $\operatorname{dig}$ & Incomplete & Progressive & $\mathrm{c}-\mathrm{v}$ & Adjacent \\
\hline 5 & $\operatorname{dog}$ & sæJ & sæg & Incomplete & Progressive & $\mathrm{c}-\mathrm{v}$ & Adjacent \\
\hline 6 & Hunting & šekar & šikar & Incomplete & Progressive & $c-v$ & Adjacent \\
\hline 7 & Sugar & Šekær & Šikær & Incomplete & Progressive & $\mathrm{c}-\mathrm{v}$ & Adjacent \\
\hline 8 & Work & car & kar & Incomplete & Progressive & $\mathrm{c}-\mathrm{v}$ & Adjacent \\
\hline
\end{tabular}

Sample 9) Bring the blanket:

re lahaf væ pætubiyar

Sample 10) The countryside is very beautiful:

dahatxæleqešange

Sample 11) Wash the dills:

Šifid re bæŠur

It can be said about the samples 9 and 10 that the vowels /e/ and /e/ in the words "lehaf" and "dehat" has transformed to the vowel /a/. Actually there is a kind of vowel assimilation to facilitate the pronunciation. In the sample 11 the middle vowel in the first syllable /e/ has become the vowel/i/.

Table 3:-examples of vowel to vowel assimilation in Mazandarani. Amoli (Marzoun Kola village)

\begin{tabular}{|c|c|c|c|c|c|c|c|}
\hline row & Meaning & \multirow{2}{*}{$\begin{array}{c}\text { Before } \\
\text { assimilation }\end{array}$} & \multirow{2}{*}{$\begin{array}{c}\text { After } \\
\text { assimilation }\end{array}$} & \multicolumn{4}{|c|}{ Assimilation type } \\
\cline { 5 - 8 } & & & & degree & direction & structure & adjacency \\
\hline 9 & Blanket & Lehaf & Lahaf & complete & retrogressive & v-v & Non-adjacent \\
\hline 10 & Countryside & dehat & dahat & complete & retrogressive & v-v & Non-adjacent \\
\hline 11 & dill & šefid & šivid & complete & retrogressive & v-v & Non-adjacent \\
\hline
\end{tabular}

\section{Methatesis}

Sample 12) There is silver in Iran nerqedæriranvejoddayne

Sample 13) Are you making fun of me?

meremaxsærekenni

Sample 14) Lock the door:

dærreqelfhaken

Sample 15) Fill the flask with water:

felaks re oudæken

Sample 16) A lot of celebrities came to the charity:

ætexæleademmæhšorbemunexeyriye

Sample 17) You got zero in the exam you took:

teemtehanikehedai serfbæei

Sample 18) Maryam went to bazar: 
mayræmburde bazar

Sample 19) Write your homework:

ŠemæqŠebænvis

Sample 20) We went to bazar to buy the ring:

æmaburdemi bazar hæqle re hayrim

In the samples 12 to 20 , as it is shown in the table the vowels have been relocated. The sonorants and continuous consonants tend to approach to the core of the syllable that is the vowel.

Table 4:-examples of methathesis in Mazandarani. Amoli (Marzoun Kola village)

\begin{tabular}{|c|c|c|c|c|}
\hline row & meaning & Phonological form & $\begin{array}{c}\text { Mazandarani } \\
\text { Amoli variety })\end{array}$ & methathesis \\
\hline 12 & Silver & noqre & nerqe & {$[\mathrm{qr}] \rightarrow[\mathrm{rq}]$} \\
\hline 13 & Make fun & maszære & maxsære & {$[\mathrm{sx}] \rightarrow[\mathrm{xs}]$} \\
\hline 14 & Lock & qofl & qolf & {$[\mathrm{fl}] \rightarrow[\mathrm{lf}]$} \\
\hline 15 & Flask & felask & felaks & {$[\mathrm{sk}] \rightarrow[\mathrm{ks}]$} \\
\hline 16 & Celebrity & mæšhor & mahšor & {$[\mathrm{sk}] \rightarrow[\mathrm{kš}]$} \\
\hline 17 & Zero & sefr & mayræm & {$[\mathrm{fr}] \rightarrow[\mathrm{rf}]$} \\
\hline 18 & Maryam & maryæm & mæq & {$[\mathrm{yr}]$} \\
\hline 19 & Homework & mæšq & hæqle & {$[\mathrm{Sq}] \rightarrow[\mathrm{qS}]$} \\
\hline 20 & Ring & hælqe & {$[\mathrm{ql}]$} \\
\hline
\end{tabular}

\section{Conclusion:-}

During its evolution, Farsi language has faced changes regarding sounds and phonemes, syntax, words and their meaning. Since the dialects are closely related to Farsi language, naturally they have also been affected by these changes. Mazandarani dialect is not an exception from this point of view. Since in assimilation the characteristics extend, it's necessary to study the characteristics and their hierarchical structure. As it was seen before, different types of assimilation processes (assimilation from the degree point of view, assimilation from the orientation point of view, assimilation from the structure point of view, and assimilation from the distance point of view) are seen in Mazandarani dialect. Vowel to vowel assimilation and vowel to consonant assimilation are more frequent than consonant to consonant assimilation. Progressive assimilation is more frequent than retrogressive assimilation. Complete and incomplete assimilation and assimilation from adjacency point of view are seen as equal.

Generally, the results obtained from the acoustic analysis of the data indicate that applying consonant to consonant assimilation in Mazandarani dialect, not only proves assimilation at production level, but also shows a kind of acoustic assimilation. Characteristics assimilation is not accidental, but it's a natural process with its rules and limitations. assimilation of the nasal /n/ with labial, coronal, and body consonants regarding the production place is not accidental, but they are influenced by the oral node. Inhomogeneity of the nasal /n/ with the pharyngeal consonants indicate that they are influenced by the structure of oral node. Also methathesis process is not as irregular and dispersed as most of the people think. But there is evidence representing the systematic nature of this process. In some cases which are not so frequent, it happens because of speech errors. In other cases and in the speech of people who are not generally educated, it is seen more frequently. In the past methathesis was considered as an irregular phenomenon merely caused by interactive errors, children's language, or phonetic changes. This perspective is mentioned in some linguistic resources.

According to this study, it is clear that while metathesis is less common than processes such as assimilation, it can occur as a regular phonological process in this language.It can be said that assimilation and metathesis processes are found in Marzoun Kola language specie like any other language specie, and the main reason for them is facility in pronunciation. They are natural and inevitable processes in most languages including Marzoun Kola language variety It also includes other phonological processes, which cannot be dealt with in this paper. While they are open to study and research. 


\section{References:-}

1. Bijan Khan, M.( 2005). phonology, optimism theory, Tehran, samt.

2. Estaji, A.(1990)." Analyzing Methathesis phonological process in Farsi language", journal of language and linguistics, year 7. NO: 1. PP. 129-145

3. Bagheri, M.(1998). The history of Farsi language, Tehran: Qaterh publications.

4. Kalbasi, I. (1991). Isfahani Farsi. first publish. Tehran. the institute of cultural studies and research.

5. Akmajian, A. \& Demers, R. \& Farmer, A. \&Harnish, R. (2010). Linguistics an introduction to language and communication, six edition. Cambridge: Massachusetts, London, England.

6. Blevins, J. \& Garret, A. (1998). "The origins of consonant-vowel methatesis". Language (74). PP. 508-556.

7. Chomsky, N. \& Halle, M. ( 1968). The Sound Pattern of English,New York: Harper \& Row.

8. Chomsky, N. \& Halle, M. ( 1965). " Some controversial questions in phonological theory". Journal of linguistics. PP. 97-138.

9. Cohn, A. (1990). "Phonetic and phonological rules of nasalization". UCLA Working papers in phonetics, 76[May]. PP. 1-224.

10. Cohn, A. (1993). "Nazalisation in English: phonology or phonetics". Phonology 10(1). PP. 43-81.

11. Crystal, D. (1997). A Dictionary of Linguistics and Phonetics. Oxford: black well.

12. Crystal, D. (2008). A Dictionary of Linguistics and Phonetics. Oxford: black well.

13. Clements, G. N. (1985). "The geometry of phonological fratures". Phonology Yearbook 2. PP. 223-252.

14. Flynn, D. (2012). Phonology the Distinctive Features of Speech Sounds. University of Calgary.

15. Hansson, GO. (2010). Consonant harmony : long- distance intraction in phonology. Berkeley, CA: University of California press.

16. Hume, E. (1998). "Methatesis in phonological theory: The case of Leti". Lingua (104). PP. 147-186.

17. Hume, E. (2006). " Diachronic aspect of metathesis". In: Encyclopedia of linguistics. ed. by Kate Brown. Elsevier Itd. PP. 506-509.

18. Jansen, W. (2007). "Phonological Voicing, Phonetic Voicing, and Assimilation in English". Language Science. Vol. 29. Issues 2-3. PP. 270-293.

19. Kord-e ZafaranluKambuziya PHD, A. (2014). Phonology Rule-Based Approaches \& their Applications in Persian, Fifth Edtion. Tehran: Samt.

20. McMahon, A. ( 2002). An Introduction to English Phonology. Edinberg University Press Ltd.

21. Odden, D. (1987). "Dissimilation as deletion in Chukchi". Proceedings- Eastern States Conference of Linguistics (ESCOL) 4. PP. 235-246.

22. Odden, D. (1994). "Adjacency parameters in phonology". Language 70(2): 289-330.

23. Spencer, A. (1996). Phonology, Oxford: Blackwell.

24. Stonham, J. ( 2006). " Metathesis". In: Encyclopedia of Linguistics. ed. by Kate Brown. Elsevier Itd. PP. 92-95.

25. Stampe, D. (1979). A dissertation on natural phonology. New York, London: Garland.

26. Trask, R. L. (2003). Historical Linguistics. Oxford University Press.

27. Wanner, D. (1989). "On metathesis in diachrony". Papers from the Annual Regional Meeting, Chicago Linguistic Society (25). PP. 434-450. 